\title{
Ion Trap Tandem Mass Spectrometry Applied to Small Multiply Charged Oligonucleotides with a Modified Base
}

\author{
Scott A. McLuckey and Sohrab Habibi-Goudarzi \\ Chemical and Analytical Sciences Division, Oak Ridge National Laboratory, Oak Ridge, Tennessee, USA
}

\begin{abstract}
Two isomeric oligodeoxynucleotide hexamers, $5^{\prime}-\mathrm{d}(\mathrm{N}-6 \mathrm{meATGCAT})-3^{\prime}$ and $5^{\prime}$-d(ATG5meCAT)-3', were subjected to analysis by electrospray and ion trap mass spectrometry. In the case of the isomer with a modified adenine, location of the modified base in the sequence was straightforward and a triple mass spectrometry experiment provided information on the identity of the modification. In contrast, the isomer with the methylated cytosine did not yield definitive information on the location or identity of the modification. Tandem mass spectrometry data in this case could indicate that the modification was present on either the third or fourth nucleoside. The two isomers represent extremes in the facility with which modified bases can be identified and located in a small oligonucleotide via multiple mass spectrometry of multiply charged anions. A preference for loss of particular bases strongly influences which structurally diagnostic ions are formed upon collisional activation. The likelihood for locating and identifying a modified base is dependent, therefore, upon the likelihood that the base is lost directly from the parent ion. (/ Am Soc Mass Spectrom 1994, 5, 740-747)
\end{abstract}

$\mathrm{D}$ ue to its high specificity, mass spectrometry has played an important role in nucleic acid research in the area of analysis of modified nucleobases and nucleic acid constituents containing modified bases. Recent reviews describe this role as well as the role of mass spectrometry in other areas of nucleic acid research [1-5]. The size of nucleic acid constituents amenable to mass spectrometric analysis has been limited largely by the inability of most ionization methods to form molecular ions in high yields. This is one reason why the vast majority of mass spectrometric studies of modified nucleic acid constituents have been devoted to nucleobases, nucleosides, and mononucleotides [5]. Fast-atom bombardment $(F A B)$ has generally provided mixed results in forming analytically useful yields of pseudomolecular ions from oligonucleotides and has not been used extensively for ionizing modified oligonucleotides. However, a few articles have appeared describing $F A B$ mass spectrometry $[6,7]$ and tandem mass spectrometry $[8-10]$ experiments that involve small modified oligonucleotides. The recent successes of matrixassisted laser desorption (MALD) [11-15] and electrospray (ES) [16-18] in ionizing oligonucleotides, however, promise to significantly expand the role of mass spectrometry in this area. The mass spectrometric analysis of modified oligonucleotides, for example, can be expected to be greatly facilitated by the advent of

Address reprint requests to Dr. S. A. McLuckey, Oak Ridge National Laboratory, P.O. Box 2008, Oak Ridge. TN 37831-6365.
MALD [19, 20] and ES [18]. Likewise, tandem mass spectrometric analysis of modified oligonucleotides should also become more tractable. Hettich and Buchanan [20], for example, have already demonstrated the tandem mass spectrometry of the [M $\left.\mathrm{H}^{+}\right]^{-}$ion formed from a modified tetramer using MALD and a Fourier transform mass spectrometer.

We recently described the tandem mass spectrometry of multiply charged anions derived from various small oligonucleotides by using electrospray combined with a quadrupole ion trap [21,22]. We found that, at least for small oligonucleotides ( $n$ up to about 12), extensive sequence information can be obtained via multiple stages of mass spectrometry. These results suggest that the identification and location of modified bases in an oligomer might be achieved by using this approach. We compare and contrast here data acquired from two isomeric methylated hexamers that illustrate both strengths and weaknesses associated with the use of multiply charged anions of oligonucleotides as the parent ions in ion trap tandem mass spectrometry and multiple mass spectrometry experiments for location and identification of modified bases.

\section{Experimental}

\section{Samples and Apparatus}

Both methylated hexamers, 5'-d(N-6meATGCAT)-3' and 5 '-d(ATG5meCAT)-3', were obtained from Phar- 
macia (Milwaukee, WI) as the sodium salts. Approximately $40 \mu \mathrm{g}$ of each hexamer were dissolved in roughly $100 \mu \mathrm{L}$ of water and diluted in $2 \mathrm{~mL}$ of highperformance liquid chromatography grade methanol to concentrations of roughly $10 \mathrm{pmol} / \mu \mathrm{L}$, which resulted in solvent composition of greater than $90 \%$ methanol. All data were acquired by direct infusion of the respective solutions at a rate of $1 \mu \mathrm{L} / \mathrm{min}$ through a 120$\mu \mathrm{m}$-i.d. electrospray needle held at a potential of -3000 to $-3500 \mathrm{~V}$. All experiments were carried out with a Finnigan-MAT (San Jose, CA) ion trap mass spectrometer modified to allow ions formed by electrospray ionization to be injected into the quadrupole ion trap $[23,24]$. A helium pressure of 1 mtorr was maintained within the analyzer vacuum system. Helium facilitates capture of injected ions and cools the ions to the center of the ion trap. Helium also serves as the target gas in collisional activation experiments.

\section{Mass to Charge Analysis and Ion Manipulation}

Each experiment began with an ion accumulation period of $0.1-0.5 \mathrm{~s}$ while the radiofrequency (rf) signal applied to the ring electrode was held at $1730 \mathrm{~V}$ zero to peak (low cutoff of $m / z$ 150). Parent ions were isolated for tandem mass spectrometry experiments by using a single ramp of the ring-electrode rf amplitude combined with resonance ejection. Ions of mass-tocharge ratio lower than that of the parent ion were ejected from the ion trap by passing the ions through the $\beta_{z}=1.0$ line via the rf amplitude ramp. Ions of mass-to-charge ratio greater than that of the parent ion were removed via dipolar resonance ejection by selecting a $6-\mathrm{V}$ peak-to-peak signal of appropriate frequency to apply to the end-cap electrodes during the rf amplitude ramp. Collisional activation was effected at a ring-electrode $\mathrm{rf}$ amplitude of $1154 \mathrm{~V}$ zero to peak (low cutoff of $m / z 100$ ) to allow for trapping of charged bases. Parent ions of different charge states were therefore activated at different $q_{z}$ values. Parent ions were typically activated for $20-40 \mathrm{~ms}$ via a single-frequency signal $(100-150 \mathrm{mV})$ applied to the end-cap electrodes at the appropriate fundamental secular frequency. Broad-band collisional activation also was employed to compare the information content of tandem mass spectra acquired via the two approaches to collisional activation. The instrument modifications required to perform this experiment have been described elsewhere [25].

Mass to charge analysis was effected by resonance ejection [26] to provide a range of $m / z \quad 100-1300$ (a mass-to-charge range extension of a factor of 2 over the nominal mass-to-charge range of the Finnigan ion trap mass spectrometer). A mass-to-charge scale correction for the data system was determined by using anions derived from the dye Direct Red 81 [23] and the $5^{-}$, $4^{-}$, and $3^{-}$ions derived from $5^{\prime}$-d(ATG5meCAT)-3'. Mass accuracy for these studies was $0.05 \%$ with this calibration. The Finnigan ion trap mass spectrometer data system provides a program to establish the ion trap scan function for an experiment that displays the spectrum in a peak profile mode. A different program uses the scan function to acquire data. The latter program permits averaging, background substraction, axis normalization, and so forth, whereas the former program does not. However, the data acquisition program does not display peaks in profile mode. Rather, the spectra are reconstructed as "stick" spectra. In so doing, the program arbitrarily assigns ions to unit masses, which can introduce errors for multiply charged ions and when the mass-to-charge range is expanded. For this reason, all mass assignments of the indicated product ions shown in the tandem mass spectra, displayed here from the data acquisition program, were verified in the peak profile mode.

Minimizing the quantity of analyte consumed was not a priority in these experiments. Therefore, the spectra shown here are the average of as many as 100 scans (up to $1 \mathrm{~min}$ of data acquisition) that yield a sample consumption of as much as $10 \mathrm{pmol}$ during data acquisition. However, in nearly all cases, an average of 10 scans provided quite satisfactory signal-tonoise ratios. Of course, the time required for setting up the experiments and tuning for collisional activation can be substantial, but the broad-band collisional activation data indicate that on-line data acquisition from injection of small quantities of analyte onto a column or flow-injection system should be feasible, as has already been demonstrated for peptides [27].

\section{Results and Discussion}

This discussion describes the information that can be obtained from mass spectral and $\mathrm{MS}^{\mathrm{n}}$ data by using electrospray ionization in conjunction with what is largely a commercially available ion trap and its data system. The only experiments that involve ion manipulation that cannot be implemented with the ion trap mass spectrometer as it is supplied by the manufacturer were those employing random noise as the means for collisional activation. The only assumption made here regarding prior knowledge about the analyte is that it is a relatively pure oligodeoxynucleotide with, at most, one modified base that is not isobaric with any of the unmodified bases.

Figure 1 shows the electrospray mass spectrum resulting from an average of four scans, shown in peak profile mode, of 5 '-d(ATG5meCAT)-3'. An essentially identical mass spectrum is obtained from the isomer $5^{\prime}$-d(N-6meATGCAT)-3'. Given the mass accuracy of about one part in two thousand, the uncertainty in the molecular weight determination is roughly plus or minus $1 \mathrm{u}$. A combination of unmodified residues that consist of $A_{2} G_{1} T_{3}$ is the only one possible within the mass interval of 1803-1805 u (meC differs from $\mathrm{T}$ by 1 $u$ ). From the mass spectrum alone, therefore, it cannot be concluded that a modified base is present in the sequence. 


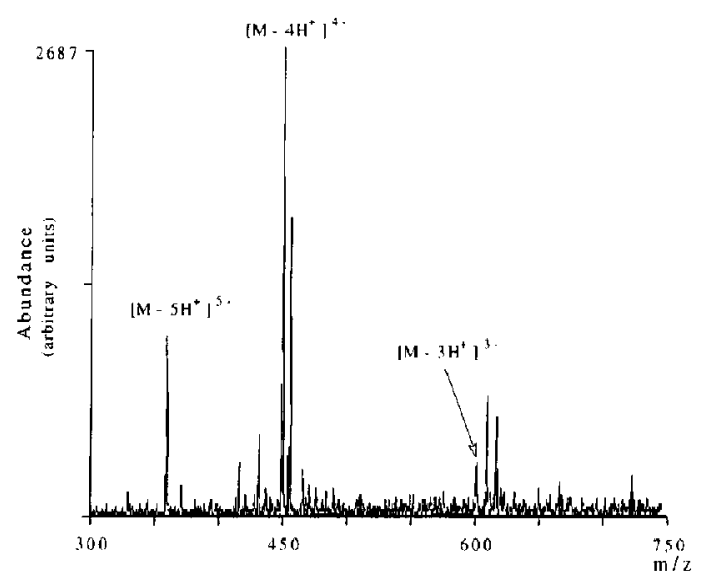

Figure 1. Negative-ion electrospray mass spectrum of $5^{\text {- }}$ d(ATG5meCAT)-3'.

Tandem mass spectrometry, in this case, is necessary to reveal the presence of a modified base because the molecular weight determination is of insufficient accuracy to do so. We have found that multiply charged oligonucleotide anions fragment under ion trap collisional activation conditions by a few simple rules. First, a base is lost either as an anion or as a neutral depending upon the charge of the parent ion. Highly charged anions show a strong preference for loss of $\mathrm{A}^{-}$ followed by loss of $\mathrm{T}^{-} . \mathrm{G}^{-}$and $\mathrm{C}^{-}$are only rarely observed as collision-induced dissociation products. These bases tend to be lost as neutrals but typically only when adenines and thymines are absent. Once a base is lost, the oligomer shows a strong tendency to fragment at the $3^{\prime} \mathrm{C}-\mathrm{O}$ bond of the sugar to which the base had been attached. This facilitates location of the base. The major ions in the tandem mass spectrum, therefore, correspond to parent ions that have lost a base and the product ions formed from the consecutive cleavage at the sugar. The second fragmentation yields complementary fragments that are labeled as [a - B] and $w$ ions $[21,22]$. The abundances of products from the second fragmentation that yield the structurally informative [a - B]- and w-type ions are, of course, dependent on the extent to which the precedent event, the loss of the base, occurs.

The selection of the two isomers studied here was based on what is anticipated, given the rules derived from tandem mass spectrometer data of a variety of small oligomers, to be two extremes in difficulty in identifying and locating modifications. Given the propensity for loss of $\mathrm{A}^{-}$, a modified adenine is expected to be the most readily located base provided the modification does not somehow affect the likelihood for A loss. On the other hand, in an attempt to sequence small oligomers it was noted that adjacent cytosines and guanines surrounded by adenines and thymines pose the greatest challenge to obtaining the full sequence. This is due to the fact that very little fragmentation tends to proceed through the channels beginning with loss of $\mathrm{G}$ and/or $\mathrm{C}$ when adenines and thymines are also present. Unless the modification alters the likelihood for base loss, a modified $C$ or $G$ with an adjacent $C$ or $G$ buried between adenines and thymines is expected to be difficult to locate. A systematic study of the effect of the nature and location on the purine or pyrimidine of the modifying species on the propensity for base loss is necessary to draw conclusions about the likelihood for locating a specific type of modification. Such a study is beyond the scope of this article, although Hocart and Schlunegger [28] have reported information regarding methylated $\mathrm{A}$ and Hettich [29] has reported relevant information regarding methylated $G$. The purpose here is to illustrate the identification and location of a base modification when the modification does not alter the rules of decomposition that hold for unmodified oligomers.

\section{$5^{\prime}-d(N-6 m e A T G C A T)-3^{\prime}$}

Figure 2 shows the tandem mass spectra obtained using single-frequency collisional activation of the $\left[\mathrm{M}-5 \mathrm{H}^{+}\right]^{5-},\left[\mathrm{M}-4 \mathrm{H}^{+}\right]^{4-}$, and $\left[\mathrm{M}-3 \mathrm{H}^{+}\right]^{3-}$ parent ions derived from $5^{\prime}$-d(N-6meATGCAT)-3'. In each spectrum, the structurally informative product ions are indicated along with a scheme that illustrates the origin of the $[a-B]$ and $w$ ions. Tandem mass spectra from parent ions of the three dominant charge states are included here to compare the information content of the tandem mass spectra as it is affected by charge state. As developed further below, most structural information comes from the tandem mass spectrum of the $\left[\mathrm{M}-4 \mathrm{H}^{+}\right]^{4-}$ parent ion due to the fact that abundant product ions are observed from dissociation channels initiated by loss of the methylated base $\left(B_{1}\right)$, the adenine at $B_{5}$, and the thymine at $B_{2}$. The loss of the thymine at $B_{6}$ also may occur, but evidence from previous work indicates that the loss of the base at the $3^{\prime}$ end of the chain is disfavored [22]. The $\left[\mathrm{M}-5 \mathrm{H}^{+}\right]^{5-}$ parent ion shows extensive decomposition that arises from the channels beginning with the loss of the $B_{5}$ adenine and by the formation of the $\mathrm{w}_{5}^{3-}$ ion. (The latter reaction probably begins with the loss of the $B_{1}$ methyladenine, but there is no direct evidence for this in the spectrum. Sequential fragmentation in some cases significantly depletes intermediate ions such as those formed by base loss [22].) More than $90 \%$ of the product ion signal can be accounted for by the sequences

$$
\begin{aligned}
{\left[\mathrm{M}-5 \mathrm{H}^{+}\right]^{5-} } & \rightarrow\left[\mathrm{M}-5 \mathrm{H}^{+}-\mathrm{A}^{-}\right]^{4-} \\
& \rightarrow\left[\mathrm{a}_{5}-\mathrm{B}_{5}(\mathrm{~A})\right]^{3-} \\
& \rightarrow\left[\mathrm{a}_{5}-\mathrm{B}_{5}(\mathrm{~A})-\mathrm{meA}^{-}\right]^{2-} \\
{\left[\mathrm{M}-5 \mathrm{H}^{+}\right]^{5-} } & \rightarrow \mathrm{w}_{5}^{3-} \\
& \rightarrow\left[\mathrm{w}_{5}-\mathrm{H}_{3} \mathrm{PO}_{4}\right]^{3-}
\end{aligned}
$$



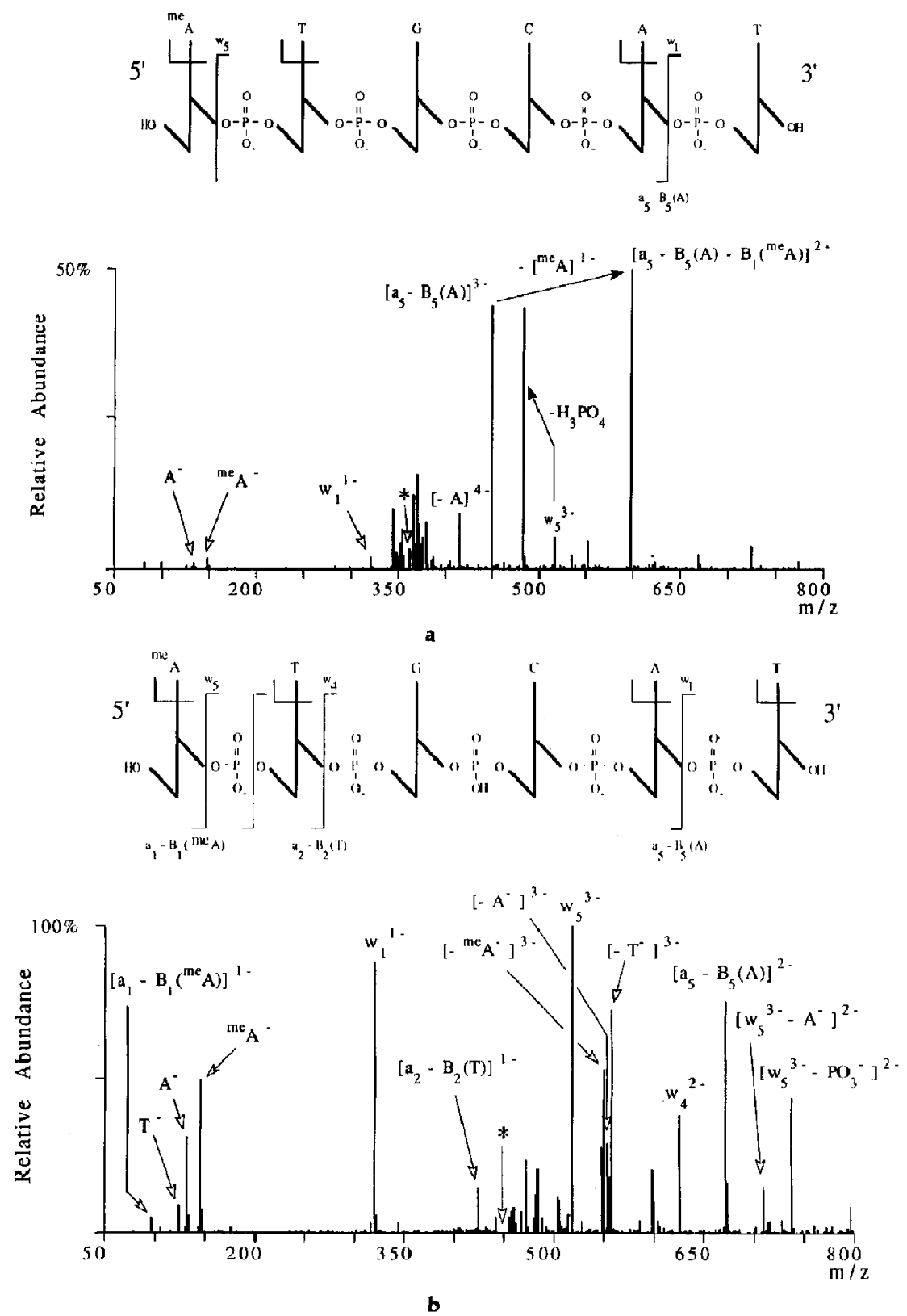

Figure 2. Tandem mass spectra of parent ions formed from $5^{t}-\mathrm{d}(\mathrm{N}-6 \mathrm{meATGCAT}) 3^{\prime}$ at charge states (a) $5^{-}$, (b) $4^{-}$, and (c) $3^{-}$. The arrow accompanying the asterisk (*) represents the mass-to-charge ratio location of the parent ion. The neutral phosphates are assigned arbitrarily. Open arrowheads with a label at the tail are used to identily some peaks. Closed arrowheads are used to indicate the genealogy of the fragments.

The masses of the complementary $\left[a_{5}-B_{5}(A)\right]$ and $w_{1}$ fragments indicate that $A$ is present on the $B_{5}$ location and that $T$ is the identity of $B_{6}$. (All $w_{1}$ masses are unique for the unmodified bases.) The loss of an $\mathrm{m} / \mathrm{z}$ 148 ion from the $\left[a_{5}-B_{5}(A)\right]^{3-}$ ion is unusual in that it does not correspond with the mass of any of the charged unmodified bases. The mass of the $a_{1}$ frag- ment, as determined by the mass difference between the parent ion and the $w_{5}$ ion, does not correspond to the mass of the $a_{1}$ fragment expected from any of the unmodified bases and is consistent with a base of 149 u. From this spectrum, therefore, it might be concluded that $B_{1}$ is a modified base and that $B_{5}$ is $A$ and $B_{6}$ is $T$. 

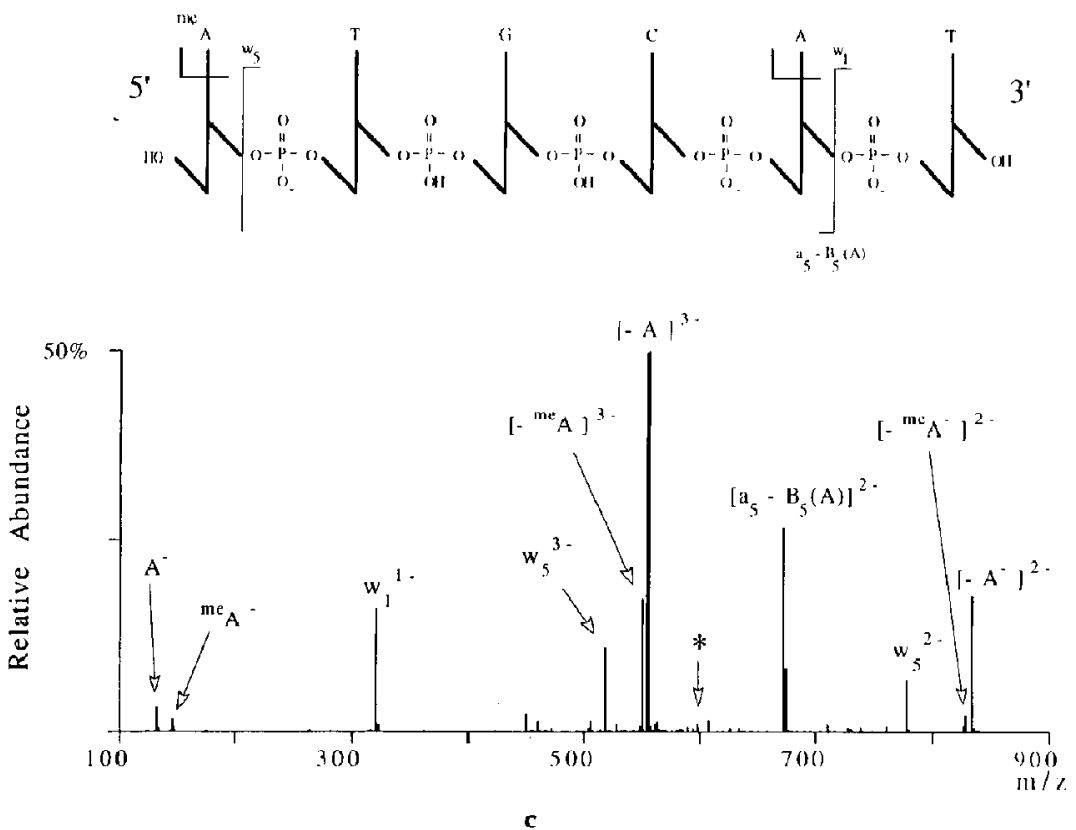

Figure 2. (Continued).

Essentially the same structural information obtained from tandem mass spectrometry of the $\left[\mathrm{M}-5 \mathrm{H}^{+}\right]^{5-}$ parent ion can be derived from the tandem mass spectrum of the $\left[\mathrm{M}-3 \mathrm{H}^{+}\right]^{3-}$ parent ion despite the fact that the spectra are remarkably different. The triply-charged parent ion fragments almost exclusively through the loss of neutral bases as the first step. In this case, losses of 135 and $149 u$ are observed. The major loss is that of 1.3511 , which corresponds to adenine. The subsequent fragmentation to yield the $w_{1}^{-}$and $\left[a_{5}-B_{5}(A)\right]^{2-}$ products establishes the identities of $B_{5}$ and $B_{6}$, as discussed above. The direct loss of $149 \mathfrak{u}$ gives strong evidence that the fragment is a base and that it is a modified base. The loss of $98 \mathrm{u}$ from this ion indicates that it is the $B_{1}$ base. Given the propensity for loss of $\mathrm{A}$ it would be tempting to conclude that the modified base is a modified $\mathrm{A}$ with the mass corresponding to a methylated $\mathrm{A}$. However, in the absence of prior knowledge as to the behavior of modified bases in a multiply charged oligonucleotide, this could only be regarded as spcculation.

The $\left[\mathrm{M}-4 \mathrm{H}^{+}\right]^{4-}$ parent ion yields complementary ions associated with loss of $\mathrm{A}^{-}, \mathrm{T}^{-}$, and the anion of $m / z 148\left(\mathrm{meA}^{-}\right)$. (The ring-clectrode $\mathrm{rf}$ amplitude during collisional activation leads to discrimination against the charged bases, particularly $\mathrm{T}^{-}$, due to their low mass-to charge ratios.) Fragmentation following the respective base losses yields useful sequence information. The formation of $w_{1}^{-}$and $\left[a_{5}-B_{5}(A)^{2-}\right]$ products following the loss of $\Lambda^{-}$establishes the identities of $B_{5}$ and $B_{6}$ as $A$ and $T$, respectively. The formation of $\mathrm{w}_{4}^{2-}$ and $\left[\mathrm{a}_{2}-\mathrm{B}_{2}(\mathrm{~T})^{-}\right]$products following loss of $\mathrm{T}^{-}$establishes $\mathrm{B}_{2}$ as $\mathrm{T}$. The loss of $98 \mathrm{u}$ from the
$\left[\mathrm{M}-4 \mathrm{H}^{+}-\mathrm{meA}^{-}\right]^{3-}$ ion to form the $\mathrm{w}_{5}^{3-}$ product, as well as the mass of the $\left[a_{2}-B_{2}(T)\right]$ fragment, both establish the location of the modified base as $B_{1}$. Very little fragmentation, however, is seen to occur via channels beginning with either loss of $G$ or $C$ in any of the spectra in Figure 2. Given the identities of $B_{1}, B_{2}$. $B_{5}$, and $B_{6}$, the combined masses associated with $B_{3}$ and $B_{4}$ are consistent with GC or CG. However, the order cannot he determined from the tandem mass spectra.

Several of the major product ions in Figure $\mathbf{2 b}$ contain the $B_{3} B_{4}$ sequence. They include $\mathrm{w}_{4}^{2-},\left[\mathrm{a}_{5}-\right.$ $\left.B_{5}(A)\right]^{2-}$, and $\mathrm{w}_{5}^{3-}$. MS $S^{3}$ experiments involving these ions might therefore reveal the order of $B_{3} B_{4}$. All three ions were used as part of $\mathrm{MS}^{3}$ experiments (data not shown) but none could provide structurally diagnostic product ion signals strong enough to answer this question unambiguously. In each case, over $95 \%$ of the product ion signal arose from losses of $\mathrm{A}^{-}, \mathrm{T}^{-}$, or $\mathrm{meA}^{-}$and subsequent dissociations. The ion observed at $m / z 796$ in the tandem mass spectrum corresponds in mass to singly charged $\mathrm{pGpCp}$ (sugar) or pCpGp(sugar) and would therefore be a good candidatc for $\mathrm{MS}^{3}$, but it was not formed in sufficient abundance for this purpose.

Although MS/MS/MS could not be used to sequence the $\mathrm{B}_{3}$ and $\mathrm{B}_{4}$ bases, additional information regarding the nature of the modified base could be obtained by the $\mathrm{MS}^{3}$ experiment involving the sequence $\left[\mathrm{M}-4 \mathrm{H}^{+}\right]^{4-} \rightarrow \mathrm{meA}^{-} \rightarrow$ ?. The product ion spectrum, shown in Figure 3 , shows a single product ion arising from a loss of $15 u$ from the $m / z 148$ ion. In the absence of benchmark tandem mass spectra of 


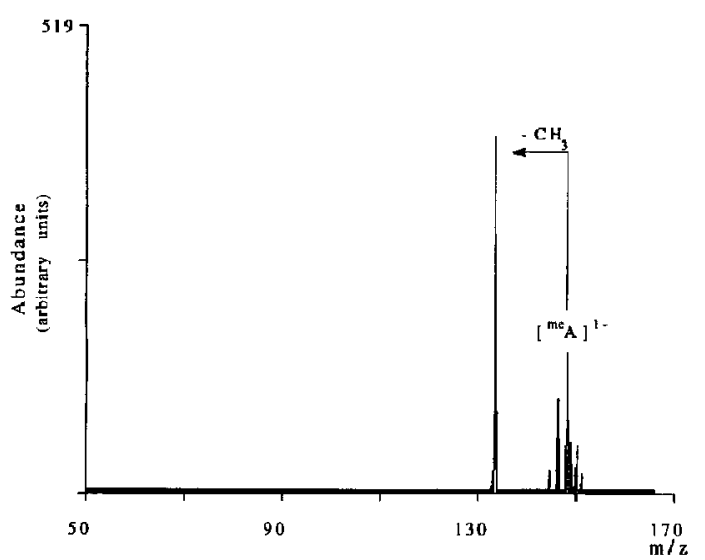

Figure 3. Triple mass spectrum acquired from the sequence $\left[\mathrm{M}-4 \mathrm{H}^{+}\right]^{4-} \rightarrow \mathrm{meA}^{-} \rightarrow$ ?, where $\mathrm{M}=5^{\prime}-\mathrm{d}\left(\mathrm{N}-6\right.$ meATGCAT)- $3^{\prime}$.

modified bases, this result alone could not be used to confirm the identity of the modified base. However, a library of tandem mass spectra of anions derived from modified bases, provided they form stable arions, could facilitate identification of the modification and, in favorable cases, its location on the base.

We have already demonstrated the use of broadband collisional activation by using a random noise generator to dissociate a variety of gaseous ions [25, 27]. A major advantage of this technique is that it obviates the frequency tuning required with singlefrequency collisional activation. This is particularly advantageous when on-line separations are coupled with the ion trap $[27,30]$. A characteristic of random noise collisional activation that sets it apart from single-frequency collisional activation is that product ions can also absorb energy from the broad-band signal and undergo collision-induced dissociation. Given the importance of sequential reactions in the decomposition of multiply charged oligonucleotides, the behavior of these ions under random noise collisional activation conditions was investigated. Figure 4 shows the tandem mass spectrum acquired from the $\left[\mathrm{M}-4 \mathrm{H}^{+}\right]^{4-}$ parent ion derived from 5'-d(N-6meATGCAT)-3' (compare Figure 2b). Apart from differences in product ion relative abundances, the data acquired under single-frequency and broad-band collisional activation conditions are essentially the same. All of the major product ions are the same in both spectra and the sequence information available from each is also the same. From this comparison, and the data for the $5^{-}$ and $3^{-}$charge states (data not shown), it can be concluded that broad-band collisional activation can be used with multiply charged oligonucleotides to avoid frequency tuning without inducing such extensive fragmentation that structural information is lost.

\section{$5^{\prime}-d(A T G 5 m e C A T)-3^{\prime}$}

Tandem mass spectrometry data were acquired by using single-frequency collisional activation for the $\left[\mathrm{M}-5 \mathrm{H}^{+}\right]^{5-},\left[\mathrm{M}-4 \mathrm{H}^{+}\right]^{4-}$, and $\left[\mathrm{M}-3 \mathrm{H}^{+}\right]^{3-}$ parent ions derived from $5^{\prime}-\mathrm{d}(\mathrm{ATG} 5 \mathrm{meCAT})-3^{\prime}$. As was noted
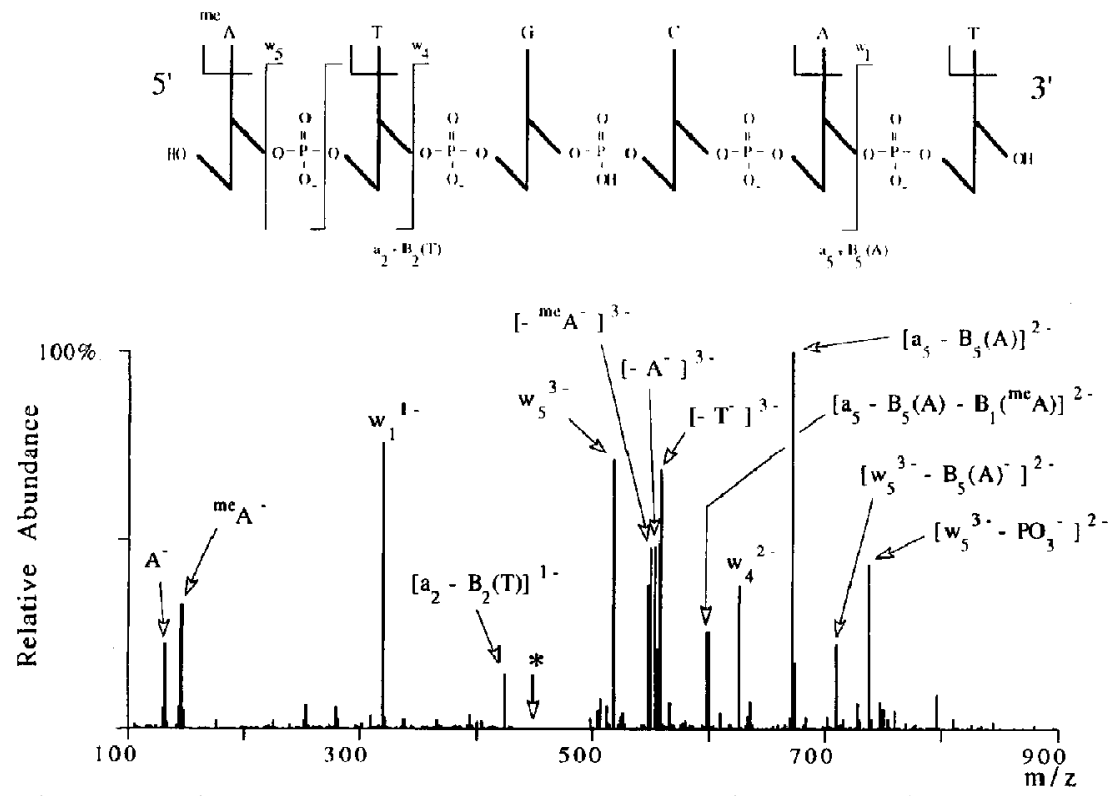

Figure 4. Tandem mass spectrum of quadruply charged $5^{\prime}-\mathrm{d}\left(\mathrm{N}-6 \mathrm{meATGCAT}-3^{\prime}\right.$ obtained by using random noise collisional activation. The arrow accompanying the asterisk ( $\left.{ }^{*}\right)$ represents the mass-to-charge ratio location of the parent ion. The neutral phosphates are assigned arbitrarily. 
above for the data for the other isomer, most structural information was available from the tandem mass spectrum of the $\left[\mathrm{M}-4 \mathrm{H}^{\prime}\right]^{4}$ parent ion, as shown in Figure 5. The most abundant product ions in this spectrum correspond to $\left[\mathrm{M}-4 \mathrm{H}^{+}-\mathrm{A}^{-}\right]^{3-}$ and $\left[\mathrm{M}-4 \mathrm{H}^{+}-\mathrm{T}^{-}\right]^{3-}$. Further decomposition of the ion resulting from loss of $A^{-}$includes loss of $98 \mathrm{u}$, confirming $A$ as $B_{1}$, and formation of $\mathrm{w}_{1}^{-}$and $\left[\mathrm{a}_{5}-\right.$ $\left.B_{5}(A)\right]^{2-}$ ions. The mass of the $w_{1}^{-}$ion indicates $T$ as $\mathrm{B}_{6}$, as in the case of the isomer. The ion arising from loss of $\mathrm{T}^{-}$fragments to yield the complementary pair $\mathrm{w}_{4}^{2-}$ and $\left[\mathrm{a}_{2}-\mathrm{B}_{2}(\mathrm{~T})\right]^{-}$indicates $\mathrm{T}$ as $\mathrm{B}_{2}$. As with the isomer, the tandem mass spectrum of the $\left[\mathrm{M}-4 \mathrm{H}^{+}\right]^{4-}$ parent yields the identities of $B_{1}, B_{2}, B_{5}$, and $B_{6}$. Likewise, the identities of $B_{3}$ and $B_{4}$ are not apparent due to the fact that no fragmentation initiated by loss of either $\mathrm{G}$ or meC was observed. As with the isomer, given the identities of $B_{1}, B_{2}, B_{5}$, and $B_{6}$, the mass associated with $B_{3} B_{4}$ can narrow the possibilities for the composition of the central two bases. Furthermore, the absence of loss of either $\mathbf{B}_{3}$ or $\mathbf{B}_{4}$ from the oligonucleotide is suggestive evidence that neither adenine nor thymine are $B_{3}$ or $B_{4}$.

The $w_{5}^{3-}, w_{4}^{2-}$, and $\left[a_{5}-B_{5}(A)\right]^{2-}$ product ions all contain the $\mathrm{B}_{3} \mathrm{~B}_{4}$ sequence and would therefore be candidates for $\mathrm{MS}^{3}$ experiments to determine the identities and sequence of these bases. A MS ${ }^{3}$ experiment involving the $\left[\mathrm{a}_{5}-\mathrm{B}_{5}(\mathrm{~A})\right]^{2-}$ ion was performed, but essentially all of the product ion signals were associated with loss of neutral adenine. The $\mathrm{w}_{5}^{3-}$ and $\mathrm{w}_{4}^{2-}$ ions were not subjected to $\mathrm{MS}^{3}$. Given the behavior of the analogous ions formed from the isomers under $\mathrm{MS}^{3}$ conditions, these ions are expected to fragment predominantly via loss of $B_{5}(A)$ and subsequent dissociation.

\section{Conclusions}

The data presented here illustrate both favorable and unfavorable cases for locating and identifying modified bases in a small oligonucleotide via ion trap MS $^{n}$ of multiply charged anions. The strong preference for losses of particular bases makes locating modified bases that happen to be lost upon collisional activation a relatively straightforward task. On the other hand, if the modification is present on a base that is not lost upon collisional activation, the task is much more difficult. Possible exceptions are the bases on the terminal sugars. The masses of the $\left[a_{2}-B_{2}\right]$ and $w_{1}$ ions can provide information on the identities of the $5^{\prime}$ and $3^{\prime}$ bases, respectively, even when they are not lost. In favorable cases, $\mathrm{MS}^{n}$ experiments might be used to locate modified bases when the tandem mass spectrum does not reveal this information. However, when product ion charge tends to be partitioned into reaction channels other than those of interest, as was the case in this study, there may be insufficient numbers of ions to allow for the neressary number of stages of mass spectrometry [31].
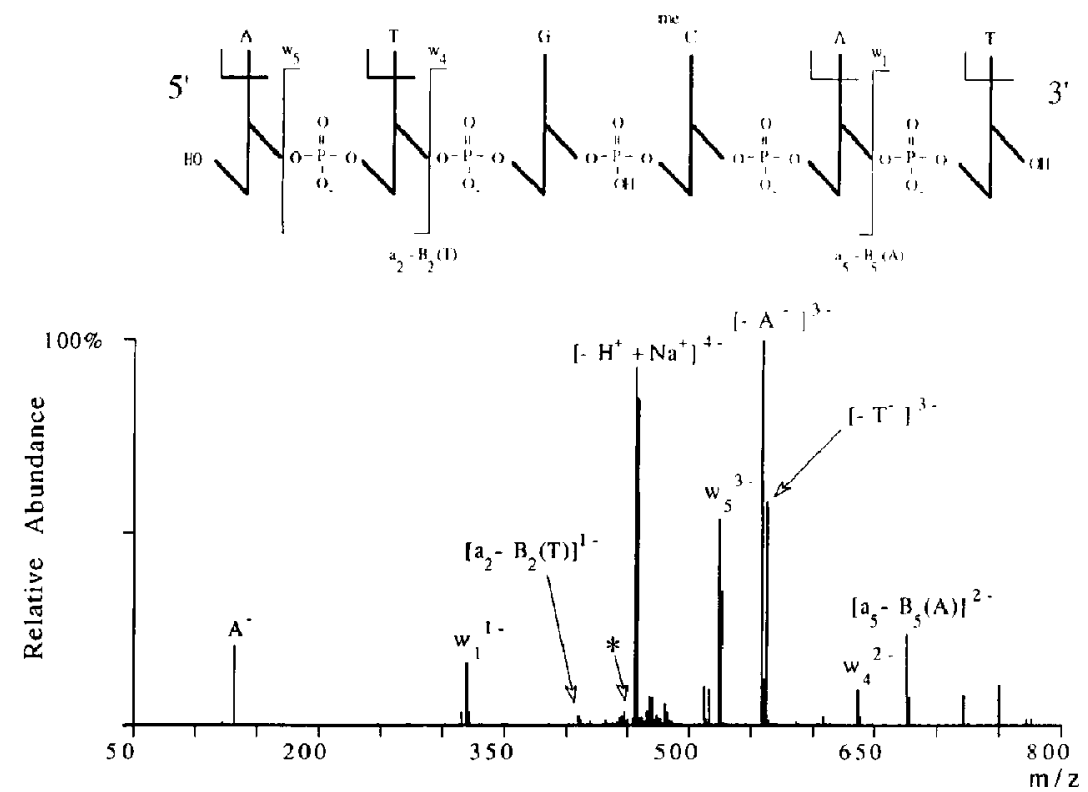

Figure 5. Tandem mass spectrum of quadruply charged 5'-d(ATG5meC $\Lambda \mathrm{T})-3$ '. The arrow accompanying the asterisk (*) represents the mass-to-charge ratio location of the parent ion. Note that the $\left[\mathrm{M}-5 \mathrm{H}^{+}+\mathrm{Na}^{+}\right]^{4-}$ ion was not removed prior to collisional activation of $\left[\mathrm{M}-4 \mathrm{H}^{+}\right]^{4-}$. The neutral phosphates are assigned arbitrarily. 


\section{Acknowledgments}

This work was supported by the National Institutes of Health under grant R01 GM45372. Oak Ridge National Laboratory is managed for the U.S. Department of Energy under Contract DE-AC05-84OR21400 by Martin Marietta Energy Systems, Inc. SHG acknowledges support through an appointment to the Oak Ridge National Laboratory Postdoctoral Research Associates Program administered jointly by the Oak Ridge Institute for Science and Education and Oak Ridge National Laboratory.

\section{References}

1. McCloskey, J. A.; Crain, P. F. Int. I. Mass Spectrom. Ion Processes 1992, 118,119, 593.

2. Crain, P. F. Mass Spectrom. Rev. 1990, 9, 505.

3. Schram, K. H. In Mass Spectrometry; Lawson, A. M., Ed.; Walter de Gruyter: New York, 1989, p 507.

4. McCloskey, J. A. In Methods in Enzymology, Vol. 193; McCloskey, J. A., Ed.; Academic: New York, 1990; chap. 41.

5. Chiarelli, M. P.; Lay, J. O., Jr. Mass Spectrom. Rev. 1992, 11, 447.

6. Lasko, D. D.; Basu, A. K.; Kadlubar, F, F, Evans, F. E.; Lay, J. O., Jr.; Essigmann, J. M. Biochemistry 1987, 26, 3072.

7. Iden, C. R,; Rieger, R. A. Biomed. Environ. Mass Spectrom. 1989, 18,617

8. Dino, J. J., Jr.; Guenat, C. R.; Tomer, K. B.; Kaufman, D. G. Rapid Commun. Mass Spectram. 1987, 1, 69.

9. Tomer, K. B.; Guenat, C. R.; Dino, J. J., Jr.; Deterding, L. J. Biomed. Environ. Mass Spectrom. 1988, 16, 3072.

10. Martin, L. B., III; Schreiner, A. F; van Breemen, R. B. Anal. Biochem. 1991, 193, 6.

11. Hillenkamp, F.; Karas, M.; Ingendoh, A.; Stahl, B. In Biological Mass Spectrometry; Burlingame, A. L; McCloskey, J. A., Eds.; Elsevier: New York, 1990; p 49.

12. Karas, M.; Bahr, U. Mass Spectrom. Rev. 1991, 10, 335.

13. Huth-Fehre, T.; Gosine, J. N.; Wu, K. J.; Becker, C. H. Rapid Commun. Mass Spectrom. 1992, 6, 209.
14. Schieltz, D. M.; Chou, C.; Luo, C.; Thomas, R. M.; Williams, P. Rapid Commun. Mass Spectrom. 1992, 6, 631.

15. Tang, K.; Allman, S. L.; Jones, R. B.; Chen, C. H.; Araghi, S. Rapid Commun. Mass Spectrom. 1992, 7, 63.

16. Covey, T. R.; Bonner, R. F.; Shushan, B. I.; Henion, J. D. Rapid Commun. Mass Spectrom. 1988, 2, 249.

17. Smith, R. D.; Loo, J. A.; Edmonds, C. G.; Barinaga, C. J.; Udseth, H. R. Anal. Chem. 1990, 62, 882.

18. Stults, J. T.; Marsters, J. C. Rapid Commun. Mass Spectrom. $1991,5,359$.

19. Hettich, R.; Buchanan, M. V. Int. J. Mass Spectrom. Ion Process. 1991, 111, 365 .

20. Hettich, R.; Buchanan, M. V. J. Am. Soc. Mass Spectrom. 1991 , 2,402 .

21. McLuckey, S. A.; Van Berkel, G. J.; Glish, G. L. J. Am. Soc. Mass Spectrom. 1992, 3, 60.

22. McLuckey, S. A.; Habibi-Goudarzi, S. J. Am. Chem. Soc, 1993, $115,12085$.

23. Van Berkel, G. J.; McLuckey, S. A.; Glish, G. L. Anal. Chem. 1990, 62, 1284.

24. McLuckey, S. A.; Van Berkel, G. J.; Glish, G. L.; Huang, E. C.; Henion, J. D. Anal, Chem. 1991, 63, 375.

25. McLuckey, S. A.; Goeringer, D. E.; Glish, G. L. Anal. Chem. 1992, 64, 1455.

26. Kaiser, R. E., Jr.; Louris, J. N.; Amy, J. W.; Cooks, R. G. Rapid Commun. Mass Spectrom. 1990, 3, 225.

27. Ramsey, R. S.; Goeringer, D. E.; McLuckey, S. A. Anal. Chem. $1993,65,3521$.

28. Hocart, C. H.; Schlunegger, U. P. Rapid Commun. Mass Spectrom. 1989, 3, 249.

29. Hettich, R. L. Biomed. Envirnn. Mass Spectrom. 1989, 18, 265.

30. Van Berkel, G. J,; Goeringer, D. E. Anal. Chim. Acta 1993, 277, 41.

31. McLuckey, S. A.; Glish, G. L.; Van Berkel, G. J. Int. J. Mass Spectrom. Ion Process. 1991, 106, 213. 